\title{
Research and Modeling of the Bidirectional Half-Bridge Current-Doubler DC/DC Converter
}

\author{
Liang Huang, Xinchao Dong, Changjun Xie, Shuhai Quan, and Yang Gao \\ School of Automation, Wuhan University of Technology, Wuhan, China \\ Correspondence should be addressed to Xinchao Dong; 403491924@qq.com
}

Received 19 October 2016; Revised 18 December 2016; Accepted 4 January 2017; Published 1 February 2017

Academic Editor: Qiaoling Tong

Copyright (C) 2017 Liang Huang et al. This is an open access article distributed under the Creative Commons Attribution License, which permits unrestricted use, distribution, and reproduction in any medium, provided the original work is properly cited.

Due to its high step-up voltage ratio, high utilization rate, and good stability, the bidirectional half-bridge current-doubler topology is widely used in lithium battery system. This paper will further analyze the bidirectional half-bridge current-doubler topology. Taking into account the fact that the current is not equal to the two times current inductance may lead to a greater transformer magnetizing current leaving the transformer core saturation occurring. This paper will focus on the circuit modeling of steady-state analysis and small signal analysis, analyzing the influence parameters for the inductor current by steady-state model and analyzing the stability of the system by the small signal model. The PID controllers and soft start algorithm are designed. Then the influence of circuit parameters on the steady state and the effect of soft start algorithm is verified, and finally the function of the soft start algorithm is achieved by the experimental prototype.

\section{Introduction}

The bidirectional half-bridge current-doubler circuit is widely used in the lithium batteries formation for it can achieve low-voltage and high-current two-way flow of energy [1-5]. This circuit topology not only has a higher voltage utilization but also can meet the requirements of the higher ratio of the buck-boost. This article mainly analyzes the steadystate and transient modeling of small signal model of the bidirectional half-bridge current-doubler circuit, the inductor current sharing issues and factors that affect the magnetic deflection of the transformer by the steady-state model, the stability of the closed loop circuit by the transient modeling of small signal model, and the design of the soft start circuit control algorithms.

\section{Analysis of the Bidirectional Half-Bridge Current-Double Topology}

The bidirectional half-bridge current-doubler topology is shown in Figure 1. The main circuit has charging mode and discharging mode of two working states. The charging mode energy flows from the bus to the battery, and the discharge mode energy is transmitted to the bus by the battery. In steady state, the duty cycle of the two MOSFET drive waveforms of the battery side is greater than $50 \%$, but in the process of the discharge mode's soft start, the two MOSFETs are not conducting situation. At this time there is no inductor current flow circuit and leakage source of the MOSFET will produce a very high-voltage spike and may breakdown the MOSFET to form the energy storage in the loop release inductance [6]. Using the principle of flyback converter for reference, adding a flyback winding to the inductor is available. When the MOSFET is not turned on, the energy of the inductor can be transferred to the high-pressure side through the flyback winding.

\section{Modeling of the Bidirectional Half-Bridge Current-Double DC/DC Converter}

3.1. Steady-State Modeling of Circuit Analysis. Before the modeling analysis, simplify the circuit. The flyback winding is mainly working in the soft start of the battery discharge mode, and the flyback winding does not work under normal operating mode, so in the analysis of steady state the two-flyback inductor is regarded as two-common inductor. In the steadystate modeling and analysis, the equivalent resistance of the 


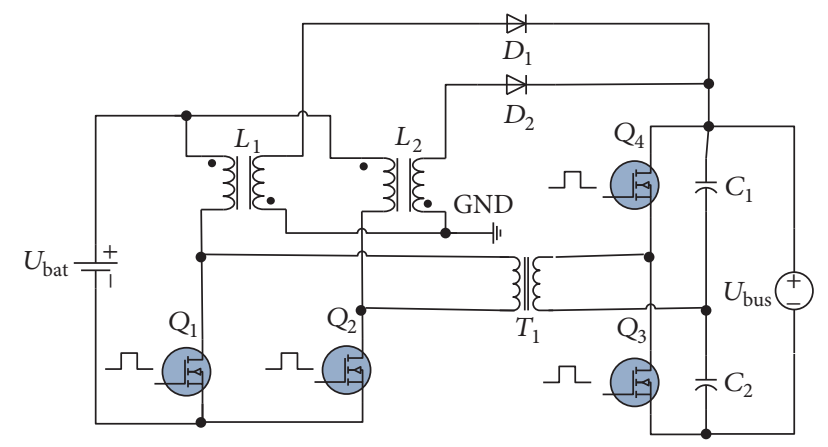

Figure 1: Circuit topology of bidirectional half-bridge currentdoubler converter.

high-voltage side $U_{\text {bus }}$ switch tube and the equivalent resistance of the transformer are converted into the equivalent resistance $R_{T}$ of the low-voltage side $U_{\text {bat }}$ of the transformer. The excitation inductance of the transformer is expressed by $L_{m}, R_{L 1}$ and $R_{L 2}$ are used to show the equivalent resistance of the low-voltage side inductance $L_{1}$ and $L_{2}$, respectively, and $R_{s 1}$ and $R_{s 2}$ are used to show the conduction resistance of $Q_{1}$ and $Q_{2}$ in the low-voltage side switch.

Here, this paper only analyzes the energy transfer from the high-voltage side to low-voltage side. $V_{\text {in }}$ represents the voltage of the bus $U_{\text {bus }} ; I_{o}$ indicates the output current when charging the battery. In the charging state of the battery, the working cycle of the circuit can be seen as 4 modes; the operating cycle of the circuit is T. Modal $1: Q_{2}$ and $Q_{3}$ are turned on; conduction time is $d_{1} T$; Modal 2: $Q_{1}$ and $Q_{2}$ are turned on; conduction time is $\left(1 / 2-d_{1}\right) T$; Modal 3: $Q_{1}$ and $Q_{4}$ are turned on; conduction time is $d_{2} T$; Modal 4: $Q_{1}$ and $Q_{2}$ are turned on; conduction time is $\left(1 / 2-d_{2}\right) T$. The equivalent model of each model is shown in Figure 2. Then calculate the equation of state of the circuit in a period. First, define the state of the circuit equation as

$$
\dot{X}=A_{i} x+B_{i} u, \quad i=(1,2,3,4),
$$

where $i$ correspond to four different working modes. The state variables and the input variables are shown in formula (2):

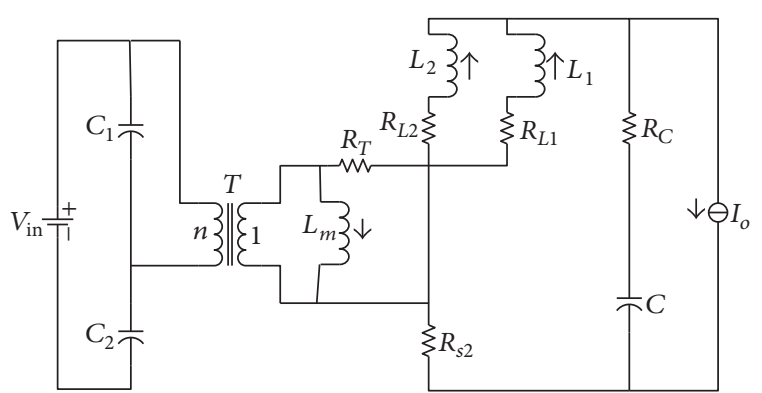

Steady state $1,\left[0, d_{1} T\right]$

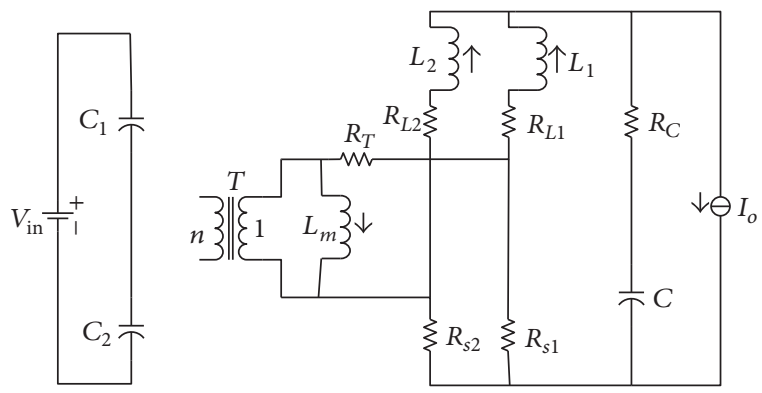

Steady state $2,\left[d_{1} T, 1 / 2 T\right]$

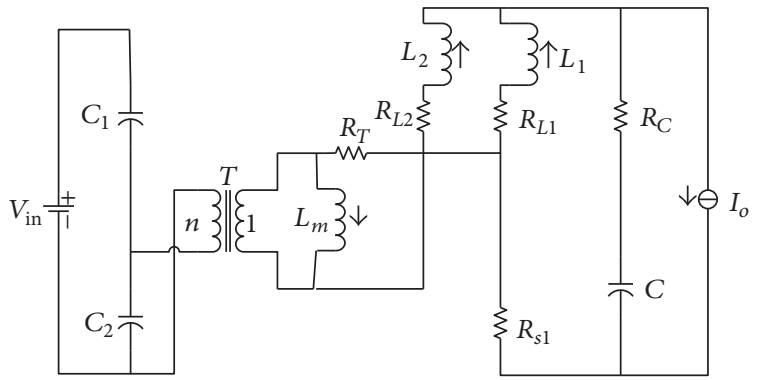

Steady state $3,\left[1 / 2 T, 1 / 2 T+d_{2} T\right]$
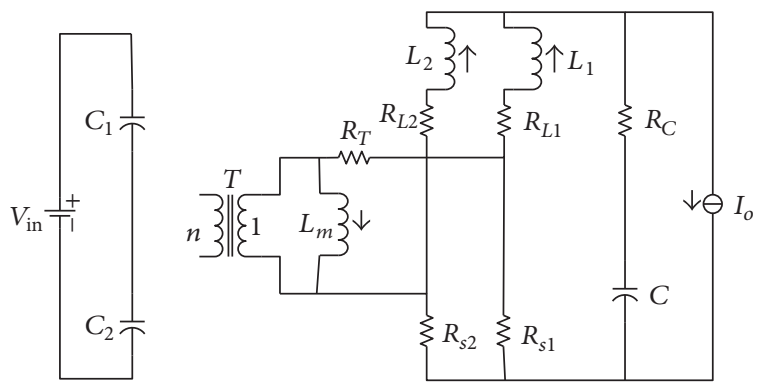

Steady state $4,\left[1 / 2 T+d_{2} T, 1 T\right]$

FIgURE 2: Working mode equivalent model.

$$
\dot{X}=\left[\begin{array}{c}
\left(C_{1}+C_{2}\right) \frac{d V_{C 1}}{d t} \\
L_{1} \frac{d i_{L 1}}{d t} \\
L_{2} \frac{d i_{L 2}}{d t} \\
C \frac{d V_{C}}{d t} \\
L_{m} \frac{d i_{m}}{d t}
\end{array}\right],
$$

$$
\begin{gathered}
x=\left[\begin{array}{c}
V_{C 1} \\
i_{L 1} \\
i_{L 2} \\
V_{C} \\
i_{m}
\end{array}\right], \\
u=\left[\begin{array}{c}
V_{\text {in }} \\
I_{0}
\end{array}\right] .
\end{gathered}
$$


According to the equivalent model of each mode in Figure 2 and the basic theory of the circuit, we can calculate the transfer matrix expression for each mode of state equation, respectively, as shown in formula (3):

$$
\begin{aligned}
& A_{1}=\left[\begin{array}{cccrc}
0 & \frac{1}{n} & 0 & 0 & \frac{1}{n} \\
\frac{1}{n}-\left(R_{T}+R_{L 1}+R_{C}+R_{s 2}\right) & -\left(R_{C}+R_{s 2}\right) & -1 & 0 \\
0 & -\left(R_{s 2}+R_{C}\right) & -\left(R_{L 2}+R_{C}+R_{s 2}\right) & -1 & 0 \\
0 & 1 & 1 & 0 & 0 \\
\frac{1}{n} & 0 & 0 & 0 & 0
\end{array}\right], \\
& A_{2}=\left[\begin{array}{ccccc}
0 & 0 & 0 & 0 & 0 \\
0 & -\left(R_{L 1}+R_{C}+R_{s 1}\right) & -R_{C} & -1 & -R_{s 1} \\
0 & -R_{C} & -\left(R_{L 2}+R_{C}+R_{s 2}\right) & -1 & R_{s 2} \\
0 & 1 & 1 & 0 & 0 \\
0 & -R_{s 1} & R_{s 2} & 0 & -\left(R_{s 1}+R_{s 2}\right)
\end{array}\right] \text {, } \\
& A_{3}=\left[\begin{array}{ccccc}
0 & 0 & \frac{1}{n} & 0 & \frac{1}{n} \\
0 & -\left(R_{L 1}+R_{C}+R_{s 1}\right) & -\left(R_{C}+R_{s 1}\right) & -1 & 0 \\
-\frac{1}{n} & -\left(R_{s 1}+R_{C}\right) & -\left(R_{T}+R_{L 2}+R_{C}+R_{s 1}\right) & -1 & 0 \\
0 & 1 & 1 & 0 & 0 \\
\frac{1}{n} & 0 & 0 & 0 & 0
\end{array}\right], \\
& A_{4}=\left[\begin{array}{ccccc}
0 & 0 & 0 & 0 & 0 \\
0 & -\left(R_{L 1}+R_{C}+R_{s 1}\right) & -R_{C} & -1 & -R_{s 1} \\
0 & -R_{C} & -\left(R_{L 2}+R_{C}+R_{s 2}\right) & -1 & R_{s 2} \\
0 & 1 & 1 & 0 & 0 \\
0 & -R_{s 1} & R_{s 2} & 0 & -\left(R_{s 1}+R_{s 2}\right)
\end{array}\right], \\
& B_{1}=\left[\begin{array}{cc}
0 & 0 \\
0 & R_{C} \\
0 & R_{C} \\
0 & -1 \\
0 & 0
\end{array}\right] \\
& B_{2}=\left[\begin{array}{cc}
0 & 0 \\
0 & R_{C} \\
0 & R_{C} \\
0 & -1 \\
0 & 0
\end{array}\right]
\end{aligned}
$$




$$
\begin{aligned}
& B_{3}=\left[\begin{array}{cc}
0 & 0 \\
0 & R_{C} \\
\frac{1}{n} & R_{C} \\
0 & -1 \\
\frac{1}{n} & 0
\end{array}\right], \\
& B_{4}=\left[\begin{array}{cc}
0 & 0 \\
0 & R_{C} \\
0 & R_{C} \\
0 & -1 \\
0 & 0
\end{array}\right] .
\end{aligned}
$$

According to the principle of state space averaging method, we analyze four modes' state equation and can get the transfer matrix of the state variables and the input variables, for $A$ and $B$. The matrices $A$ and $B$ meet such as shown in formula (4):

$$
\begin{aligned}
A= & d_{1} T A_{1}+\left(\frac{1}{2}-d_{1}\right) T A_{2}+d_{2} T A_{3} \\
& +\left(\frac{1}{2}-d_{2}\right) T A_{4} \\
B= & d_{1} T B_{1}+\left(\frac{1}{2}-d_{1}\right) T B_{2}+d_{2} T B_{3} \\
& +\left(\frac{1}{2}-d_{2}\right) T B_{4} \\
A_{2}= & A_{4} \\
B_{2}= & B_{4} .
\end{aligned}
$$

In the same way, if we analyze the energy from the low-voltage side to the high-voltage side of the discharge, the relation equation shown in formula (4) still exists. It is know that, in steady state, the inductance meet "Volt-Second" balance and the capacitance meet "Ampere-Second" balance in one cycle. So in a cycle to meet the relationship, $\dot{X}=0$, and at the same time there is a relational: $x=-A^{-1} B U$. According to this formula as well as the previously required matrix expression (3) and (4), we can get the relationship equation inductor current and transformer magnetizing current to satisfy formula (5):

$$
\begin{aligned}
& I_{L 1}=\frac{d_{2} T R_{T}+R_{L 2}}{R_{L 1}+R_{L 2}+\left(d_{1}+d_{2}\right) T R_{T}} I_{O} \\
& I_{L 2}=\frac{d_{1} T R_{T}+R_{L 1}}{R_{L 1}+R_{L 2}+\left(d_{1}+d_{2}\right) T R_{T}} I_{O}
\end{aligned}
$$

$$
I_{M}=\frac{d_{2} R_{L 1}-d_{1} R_{L 2}}{\left(d_{1}+d_{2}\right)\left(R_{L 1}+R_{L 2}\right)+\left(d_{1}+d_{2}\right)^{2} R_{T}} I_{O}
$$

From (5), this paper analyzes and draws the following conclusions: The size of the inductor current is only related to the equivalent resistance of the inductor and the duty cycle and is not related to the equivalent resistance of the MOSFET conduction at the low-voltage side; the excitation current is mainly influenced by the MOSFET conduction resistance and the driving duty cycle of the low-voltage side. When the deviation is large, it will generate a large excitation current; the excitation current lead core along the hysteresis loop shifts back and forth. When the core is saturated into the offset the switch tube will be damaged. Then you need to take transformer design and switch tube selection into account to prevent the transformer appear saturable core.

3.2. Analysis of Switch Average Model Method in Small Signal Modeling. To design the controller, the small signal modeling and analysis of the controlled object are needed [7-9]. From the analysis of the front and the equivalent model, it is found that the four modes of a working cycle of the circuit are symmetrical. According to the flow of energy per half cycle it can be equivalent to a buck or boost circuit to analyze. Here, we only analyze the small signal model of the discharge mode that is the circuit boost mode. From the structure of the circuit, we can see that the discharge mode and principle of boost circuit principle are consistent. So the load of the highvoltage side can be equivalent to the low-voltage side by the transformer ratio conversion relationship. Because the four operating modes of the circuit are symmetrical, it just needs to analyze the working mode of a bridge arm in half period to be equivalent to the small signal model of the circuit, so it can be transposed into a boost circuit modeling. The average circuit model of boost circuit is shown in Figure 3.

In Figure 3, we replace the average current of the switch device with the current source $i_{Q}$, the voltage source $v_{D}$ 


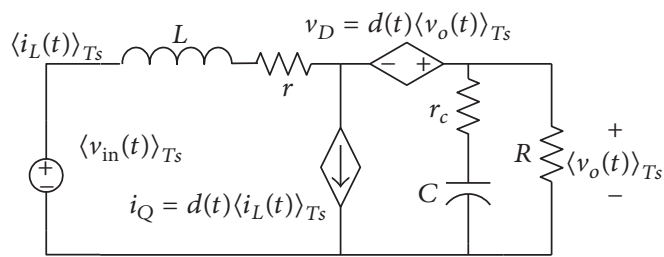

FIgURE 3: Boost circuit CCM average switching model.

instead of the average voltage of the ends of the diode. Equivalent combined resistance $r$ contains the circuit inductor DC resistance, the switch tube conduction resistance, and the diode conduction resistance. According to the principle of boost circuit we can obtain formula (6):

$$
\begin{gathered}
i_{Q}=d(t)\left\langle i_{L}(t)\right\rangle_{T s}, \\
v_{D}=d(t)\left\langle v_{o}(t)\right\rangle_{T s} .
\end{gathered}
$$

Injection disturbance in steady state: the relation equation (7) can be obtained:

$$
\begin{aligned}
i_{Q} & =(D+\widehat{d}(t))\left(I_{L}+\widehat{i_{L}}(t)\right) \\
& =D I_{L}+D \widehat{i_{L}}(t)+\widehat{d}(t) I_{L}+\widehat{d}(t) \widehat{i_{L}}(t), \\
v_{D} & =(D+\widehat{d}(t))\left(V_{o}+\widehat{v_{o}}(t)\right) \\
& =D V_{o}+D \widehat{v_{o}}(t)+\widehat{d}(t) V_{o}+\widehat{d}(t) \widehat{v_{o}}(t) .
\end{aligned}
$$

Among them, $\widehat{d}(t), \widehat{i_{L}}(t)$, and $\widehat{v_{o}}(t)$ are disturbance. The product term of the small signal component of $\widehat{d}(t) \widehat{v_{o}}(t)$ is the two-order microquantity. When the converter meets the small signal hypothesis, it can be ignored. Then the large signal model of boost circuit can be obtained. Eliminate a DC term in the $D I_{L}$ and $D V_{o}$, and the remaining two of the linear terms represent the role of AC small signal. Small signal model is shown in Figure 4.

In Figure 4, the parameters of each component are $s$ domain parameters. According to KCL and KVL theorem as formula equations (8), we have the following:

$$
\begin{aligned}
i_{L}(s)= & D i_{L}(s)+d(s) I_{L}+i_{o}(s)-i_{L}(s) Z_{1}+D v_{o}(s) \\
& +d(s) V_{o}-v_{o}(s)=0, \\
i_{o}(s)= & \frac{v_{o}(s)}{Z_{2}} \\
I_{L}= & \frac{I_{o}}{(1-D)}, \\
Z_{1}= & s L+r, \\
Z_{2}= & \left(\frac{1}{s C}+r_{c}\right) \| R .
\end{aligned}
$$

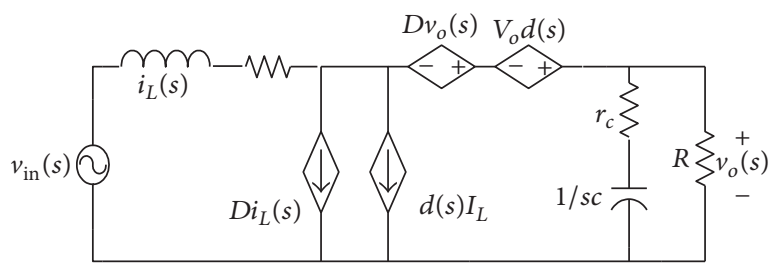

FIgURE 4: Boost circuit CCM small signal model.

By equation group (8) we can get the traditional function of the current to the duty cycle, such as formula (9):

$$
\begin{aligned}
G(s) & =\frac{i_{L}(s)}{d(s)}=V_{o} \frac{1+Z_{2} / R}{Z_{2}(1-D)^{2}+Z_{1}} \\
& =V_{o} \frac{1+\left[\left(1 / s C+r_{c}\right) \| R\right] / R}{(1-D)^{2}\left[\left(1 / s C+r_{c}\right) \| R\right]+s L+r} .
\end{aligned}
$$

The design parameters of the circuit are as follows: transformer ratio: $n=1.4$, inductance: $L=100 \mu \mathrm{H}$, and capacitance: $C=450 \mu \mathrm{F}$. Converter efficiency is 0.9 , the transformer is regarded as a voltage amplifier, the highvoltage side voltage is converted to the low-voltage side, and the input voltage is the lowest value: $U_{\text {bat }}=43 \mathrm{~V}$; we can get

$$
\begin{aligned}
& V_{o}=\frac{V_{\text {bus }}}{2 n}=138.18 \mathrm{~V}, \\
& R=\frac{V_{o}^{2}}{\left(\eta P_{\text {in }}\right)}=7.89 \Omega, \\
& D=1-\frac{V_{\text {in }}}{V_{o}}=0.689 .
\end{aligned}
$$

Since the inductance is small, the inductor DC resistance is also small, the conduction resistance of MOSFET is about several milliohms, and, in order to facilitate the calculation, these three small items can be ignored, the system's transfer function is as follows:

$$
G(s)=1.384 \cdot 10^{6} \frac{s+644}{s^{2}+381.19 s+2.146 \cdot 10^{6}} .
$$

\section{Simulation Analysis}

4.1. Steady-State Simulation Model. This paper simulates the circuit analysis by PISM software; circuit simulation parameters are as follows: inductance value is $100 \mu \mathrm{H}$, the transformer ratio and winding counterattack is 1.4 , the low-voltage side of the input voltage is $48 \mathrm{~V}$, output power is $6 \mathrm{~kW}$, the output voltage control is $380 \mathrm{~V}$. Here it has the results of the modeling circuit steady-state simulation analysis, simulation waveforms shown in Figure 5. According to Figure 5, we can see that increasing the equivalent on-resistance of the low-voltage side of the MOSFET transistor has no effect on the inductor current, changing the size of the value of the equivalent resistance of the inductor $L_{1}$ or changing the high-pressure side of the two MOSFETs duty ratio will make two MOSFETs turn-on time show subtle differences that will 


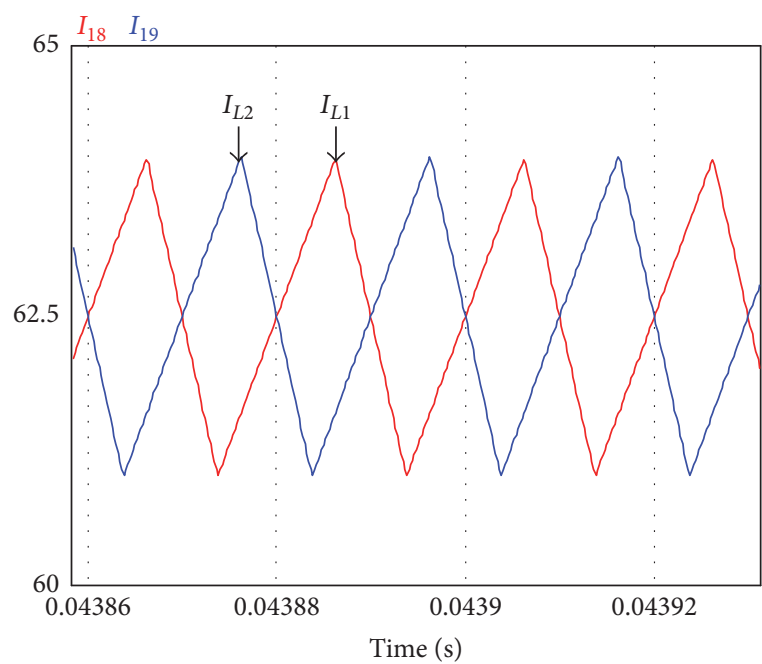

(a) The current waveform when the inductance equivalent resistances are not equal

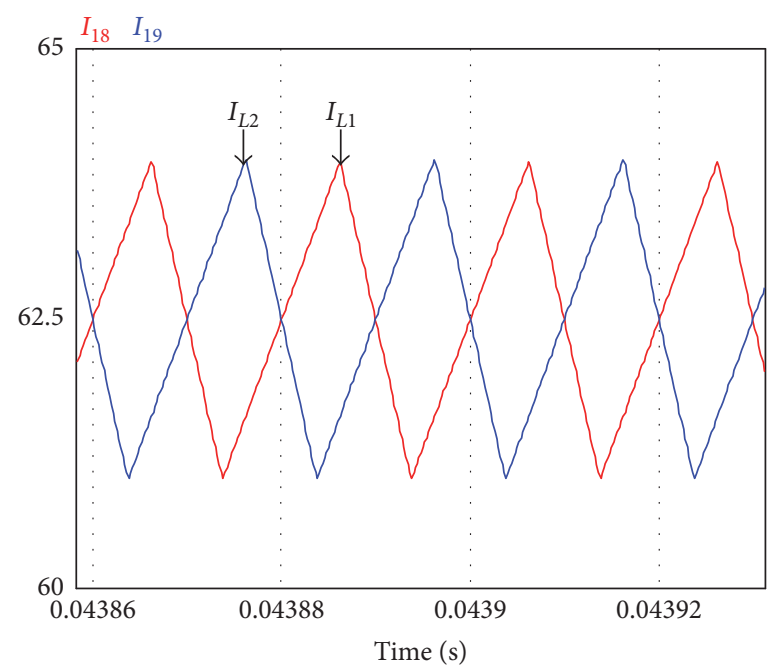

(b) Unequal MOSFET on-resistance current waveform

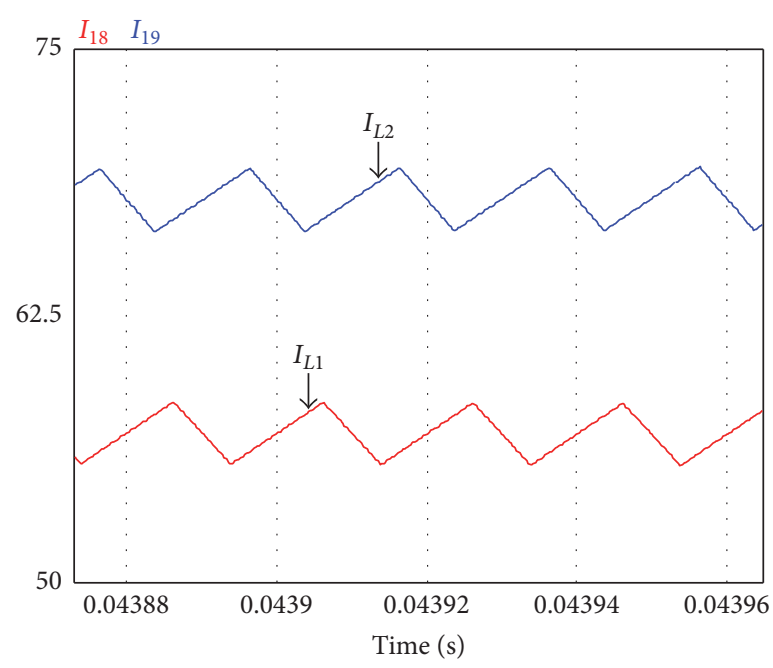

(c) Current waveform when the duty cycles are unequal in size

FIGURE 5: Inductor current simulation waveforms.

make the current size of the two inductors show the deviation, and the duty ratio deviation will have greater effect on the inductor current deviation.

4.2. PID Controller Design. The PID controller of the system is designed through the system transfer function of small signal [10-12]. The current in the system is realized by controlling the duty cycle, and the duty cycle control is the use of PID control. There are many methods for tuning the parameters of PID controller; we can according to the specific needs choose the suitable parameter tuning method. Here this paper uses a more efficient way, Matlab software provides the SISOTOOL tool, and it corrects the PID parameters of the transfer function of the system directly by the software. Through the Matlab software, we can get the PID parameters: the proportion of the parameter $K p$ is infinitesimal; the integral parameter $K i$ is 0.336 . The PID controller's transfer function is as follows:

$$
G(s)_{\mathrm{PID}}=0.336 \frac{1}{s} .
$$

Then, the step response of the system is compared with that of the system without PI. From Figure 6, we can see that after the addition of PI the system overshoot is negligible, and the steady-state error of the system is significantly reduced a lot, while the steady-state error of the system without PI is larger.

4.3. Soft Start Algorithm Design. When the circuit starts, initial duty ratio is too high which will lead to the start process being not smooth, and also large duty ratio will make the circuit voltage and current overshoot and oscillation. This will not only make the system instable and damage the whole circuit system, but also cause a huge impact to the power 


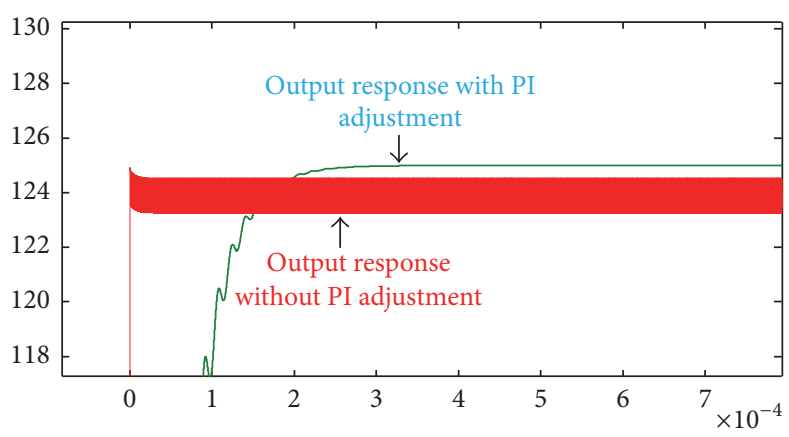

FIGURE 6: Step response simulation waveforms.

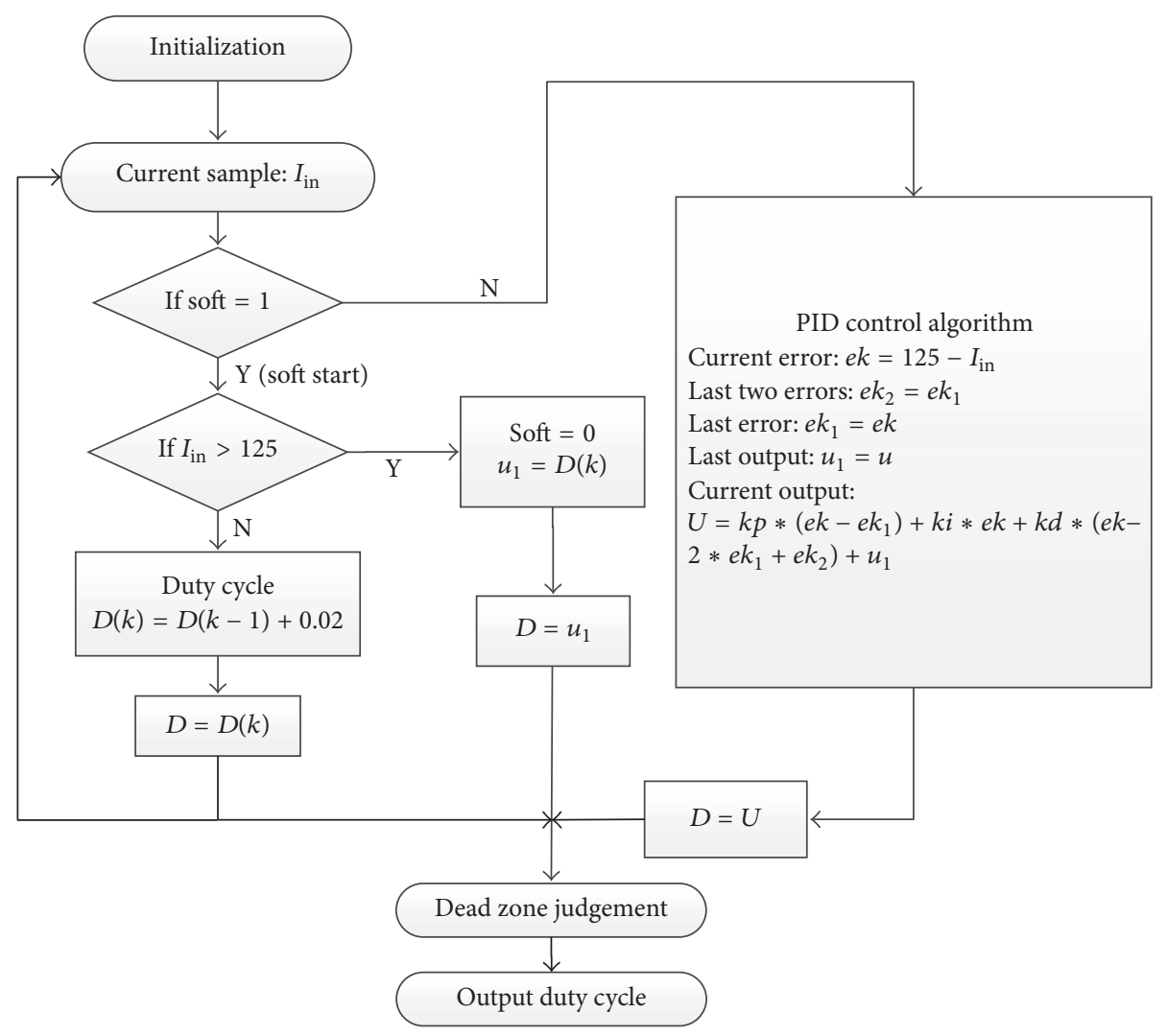

FIGURE 7: Soft start algorithm flowchart.

grid, affecting the quality of power supply; this is the so-called hard start [13]. Therefore, in order to reduce the impact of large current and high voltage, it needs to add soft start to the start process, so that the current can smoothly rise and reduce the shock of the current and voltage. The general soft starting circuit is realized by controlling the voltage of the error amplifier. Here we use a new type of soft start algorithm and control the duty cycle soft start by a program algorithm. At the start of the circuit, drive switch tube of duty ratio by 0 slowly increased, and, compared with the setting target current value, until the current in low-voltage side reached the setting current, then clear the soft start mark and closed soft start; the program jumps from the soft start mode to the normal PI control mode. Soft start algorithm flowchart is shown in Figure 7. Judging by the dead zone to limit the maximum and minimum output duty cycle, to ensure the two MOSFETs of the high-voltage side will not appear shootthrough.

The soft start algorithm has been simulated, and the simulation results are shown in Figure 8. From the graph, can see that the MOSFET duty cycle is increased slowly at the start of the circuit, and the low-voltage side current is gentle from 0 to reach the target value of $125 \mathrm{~A}$ and the soft start process is finished. The simulation results shown in Figure 8 can be seen with the benefits of soft start; soft start process can make the MOSFET current and voltage gentle to reach the steady-state value and will not produce a larger current or voltage shock. This can effectively avoid the electric current 

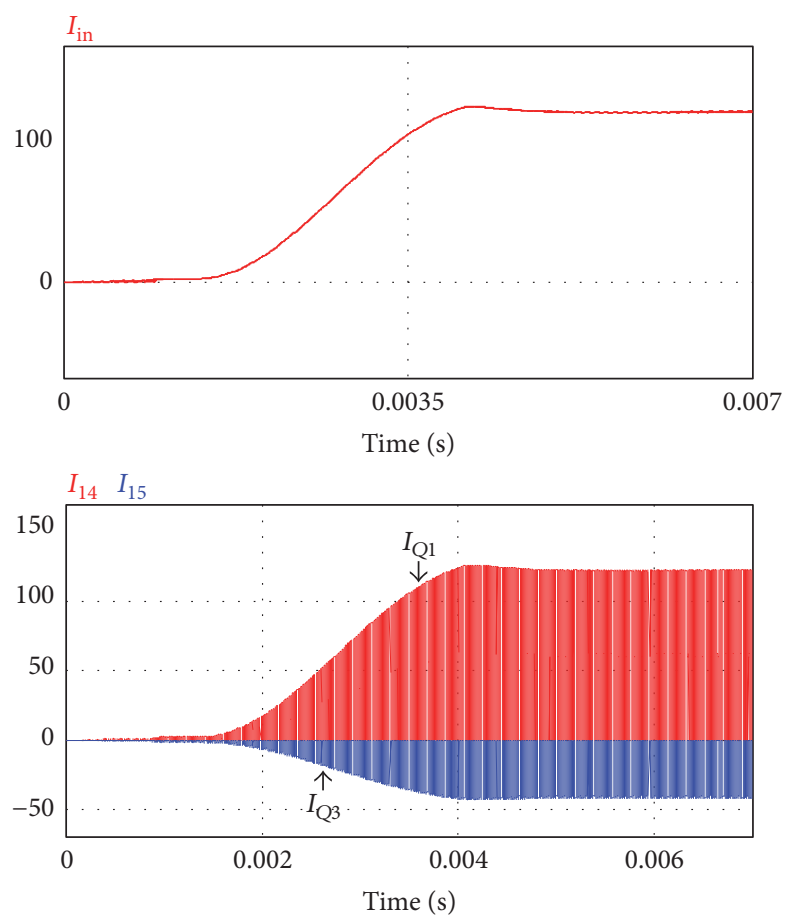

FIGURE 8: Low-voltage side current waveform and MOSFET current of soft start.

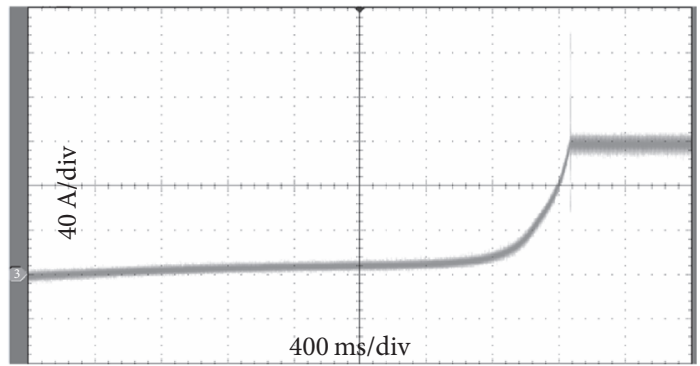

(a) Output current soft start waveforms

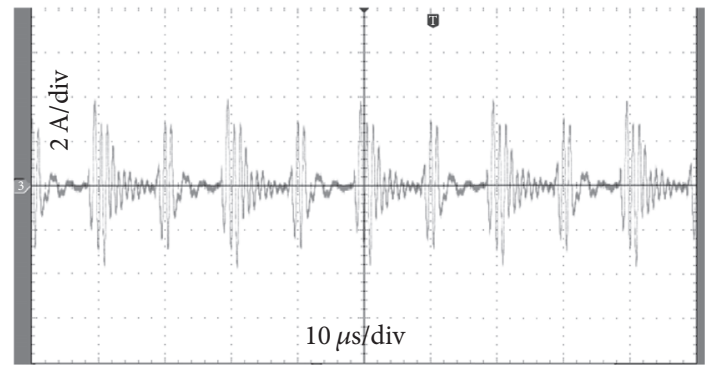

(b) Inductor current waveform

FIgURE 9: Experimental waveforms.

and voltage transition instant damage MOSFET, so as to effectively protect the MOSFET stable and reliable operation of the circuit. So the role of soft start is very important in the process of starting.

\section{Experiment Analysis}

Laboratory system is built on the lithium battery charge and discharge test; the circuit parameters are as follows: the lowvoltage side of the MOSFET model is IXTQ100N25P, and, using the two MOSFETs model parallel to ensure adequate safety margin, the high-voltage side of MOSFET model is IPP60R074C6. Flyback inductance value is $146 \mu \mathrm{H}$, with core Magnetics Kool 77083 model core. Master controller uses TMS320F28335 chip. MOSFET drive voltage is $12 \mathrm{~V}$, and the switching frequency is $40 \mathrm{kHz}$. Current test mode: the system input voltage of the battery is $48 \mathrm{~V}$, input current is $120 \mathrm{~A}$, and full load test waveforms are as shown in Figure 9. Figure 9(a) shows the soft start current waveform, the start time is 3.4 seconds, and a smooth current reaches a target current value; Figure 9(b) shows the inductor current waveform, the peak current is $8.4 \mathrm{~A}$, and current ripple is $14 \%$, to meet the design requirements.

\section{Conclusion}

The steady-state model is established and the simulation results show the influence of the parasitic parameters of the circuit on the circuit stability. By soft start algorithm and soft start circuitry we can effectively slow down the impact of high-current circuits, thereby improving the stability of the system and increasing the life of the device. The experimental results prove the feasibility and reliability of the soft start algorithm and verify the good stability and dynamic performance of the system. 


\section{Competing Interests}

The authors declare that there is no conflict of interests regarding the publication of this paper.

\section{Acknowledgments}

This research was supported by the National Natural Science Foundation of China (51477125), and the National Key Basic Research Development Plan (973 Plan) (no. 2013CB632505), the Hubei Province Technological Innovation Major Project (2016AAA046), and the Wuhan Youth Morning Project (2016070204010155).

\section{References}

[1] D. He, Design and Implementation of Large-Capacity Lithium Battery Into the System DC/DC Converter, University of Electronic Science and Technology, Sichuan, China, 2013.

[2] R.-Y. Duan and J.-D. Lee, "High-efficiency bidirectional DCDC converter with coupled inductor," IET Power Electronics, vol. 5, no. 1, pp. 115-123, 2012.

[3] S. Park and Y. Song, "An interleaved half-bridge bidirectional dc-dc converter for energy storage system applications," in Proceedings of the 8th International Conference on Power Electronics - ECCE Asia: 'Green World with Power Electronics' (ICPE '11ECCE Asia), Jeju, Korea, June 2011.

[4] X. Zhou, P. Xu, and F. C. Lee, "A novel current-sharing control technique for low-voltage high-current voltage regulator module applications," IEEE Transactions on Power Electronics, vol. 15, no. 6, pp. 1153-1162, 2000.

[5] Y. Panov and M. M. Jovanovié, "Design and performance evaluation of low-voltage/high-current DC/DC on-board modules," IEEE Transactions on Power Electronics, vol. 16, no. 1, pp. 26-33, 2001.

[6] L. Biao, H. Liang, and H. Luo, "Analysis leakage inductance times in a half-bridge circuit flow characteristics," Power Electronics, vol. 9, pp. 69-71, 2015.

[7] B. Choi, W. Lim, S. Bang, and S. Choi, "Small-signal analysis and control design of asymmetrical half-bridge DC-DC converters," IEEE Transactions on Industrial Electronics, vol. 53, no. 2, pp. 511-520, 2006.

[8] S. Li, Y. Wang, and Z. Li, "Based on the new lithium battery into the bi-directional DC/DC topologies research and modeling," Modern Electronics Technique, vol. 10, pp. 142-154, 2011.

[9] H. Wu, Y. Lu, W. Shi, J. Zhang, and Y. Xing, "A family of non-isolated bidirectional DC-DC converter," Proceedings of the Chinese Society for Electrical Engineering, vol. 9, pp. 65-71, 2012.

[10] T. K. Psonis, P. G. Nikolakopoulos, and E. Mitronikas, "Design of a PID controller for a linearized magnetic bearing," International Journal of Rotating Machinery, vol. 2015, Article ID 656749, 12 pages, 2015.

[11] L. Guo, J. Y. Hung, and R. M. Nelms, "Comparative evaluation of sliding mode fuzzy controller and PID controller for a boost converter," Electric Power Systems Research, vol. 81, no. 1, pp. 99106, 2011.

[12] A. Bhowate and S. Deogade, "Comparison of pid tuning techniques for closed loop controller of DC-DC boost converter," International Journal of Advances in Engineering and Technology, vol. 8, no. 1, pp. 2064-2073, 2015.
[13] M. Tian, J. Wu, L. Hao, F. Xiong, J. Zhang, and J. Zhang, "Based on the multi-port DC/DC converter for battery energy storage system soft-start control strategy," Power System Technology, vol. 9, pp. 245-247, 2015. 


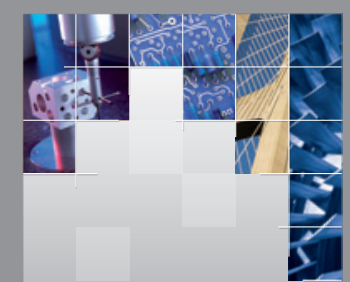

\section{Enfincering}
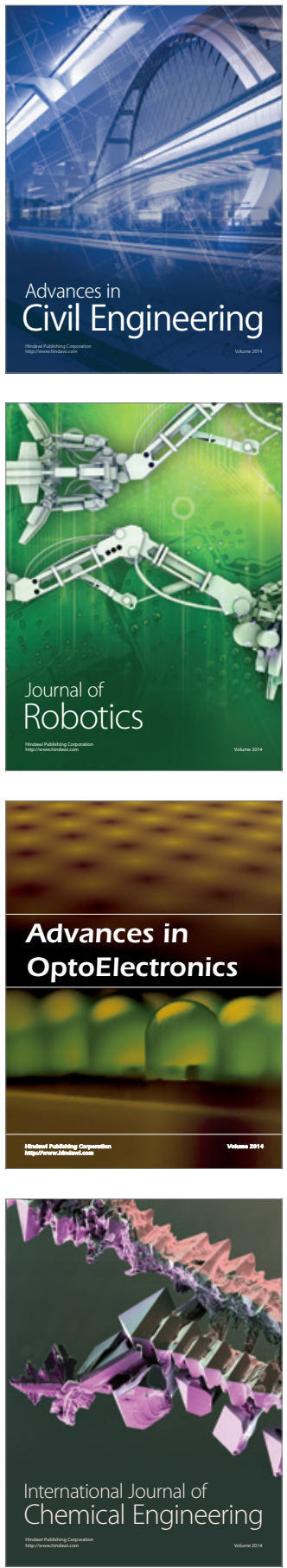

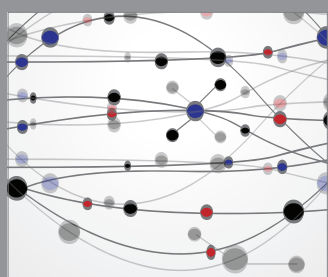

The Scientific World Journal

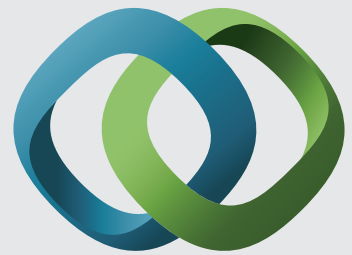

\section{Hindawi}

Submit your manuscripts at

https://www.hindawi.com
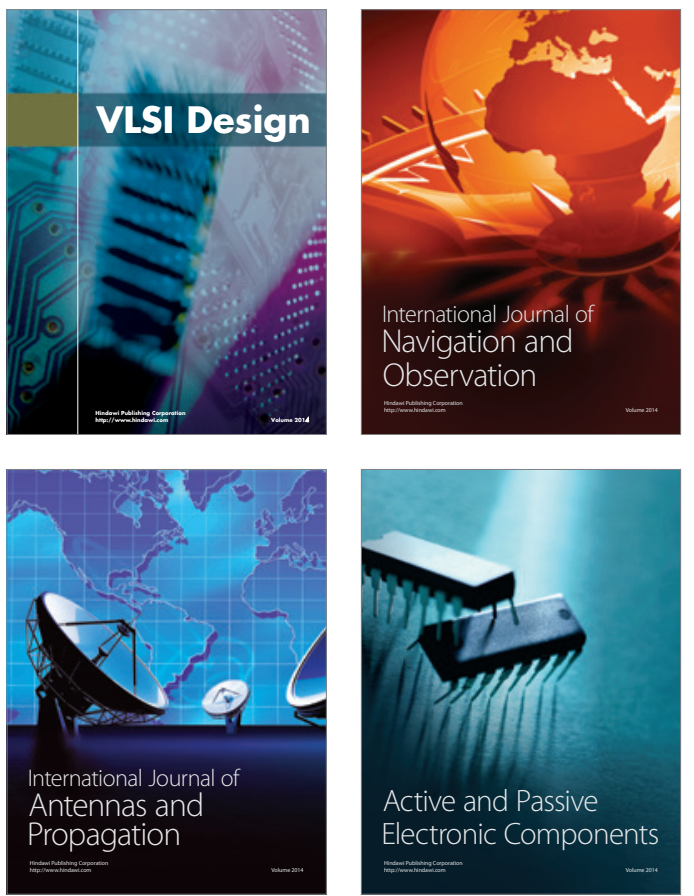
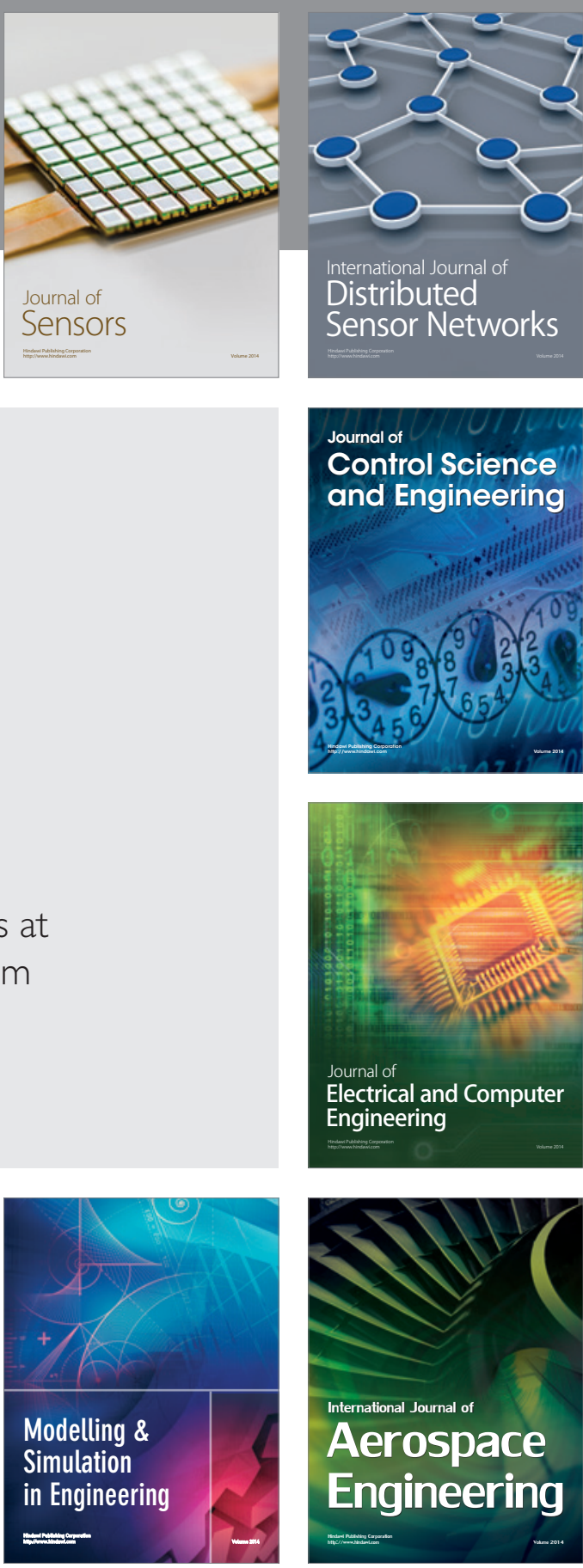

International Journal of

Distributed

Sensor Networks

$-$

Joumal of

Control Science

and Engineering
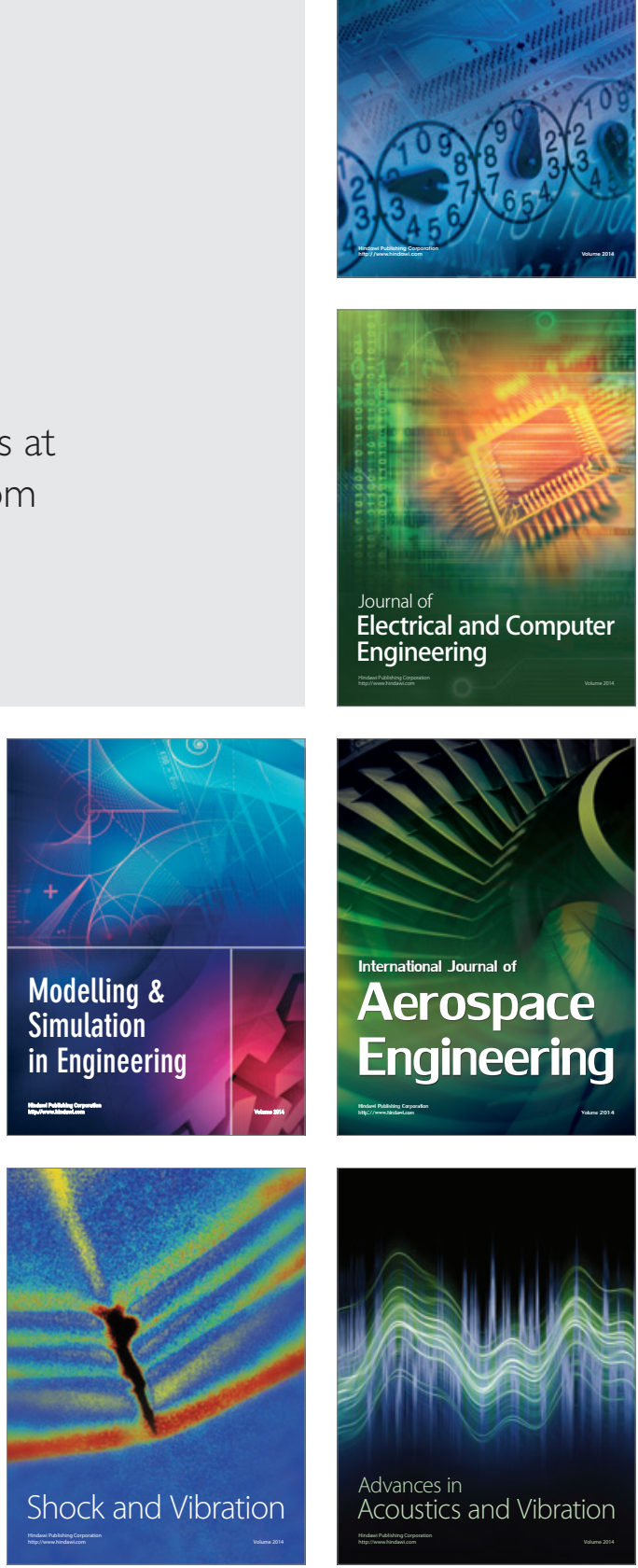